\title{
Excretion of Fat after Vagotomy Alone and in Combination with Pyloroplasty: an Experimental Study
}

\author{
C. WASTELL, $*$ F.R.C.S.
}

Brit. med. F., 1966, 1, 1198-1199

It has been shown (Wastell and Ellis, 1966) that after total or anterior selective vagotomy and pyloroplasty in patients with chronic duodenal ulcer there is a rise in excretion of faecal fat. In half of the patients studied this was to abnormal levels.

The present study was undertaken to separate the individual effects of vagotomy and of pyloroplasty on the excretion of fat. Dogs were investigated, the excretion of fat in the faeces being measured before and after total vagotomy, anterior selective vagotomy, anterior selective vagotomy and pyloroplasty, and pyloroplasty alone.

\section{Materials and Methods}

The dogs were male adult mongrels from 10 to $20 \mathrm{~kg}$. in weight. They were housed in kennels with either a concrete or a smooth metal floor, a raised wooden sleeping-shelf being situated at one end.

Faeces were collected for five days so as to obtain a representative daily stool excretion. At the end of the faecal collection the total excretion of fat was estimated by the technique of Kamer, Huinink, and Weyers (1949). For one day preceding and for the total duration of the collection the dogs were fed a diet consisting of $1.3 \mathrm{~g}$. of fat and 200 calories $/ \mathrm{kg}$. bodyweight. The diet was composed of boiled, sliced ox liver.

Total vagotomy was performed on 10 dogs by the transthoracic route, via the left sixth interspace. Anterior selective vagotomy was accomplishod, also in 10 dogs, via a long leftsubcostal incision. The hepatic branches of the anterior vagus were identified without difficulty, and preserved, as they passed in the lesser omentum to the porta hepatis. Most of the dogs after vagotomy without drainage vomited in the immediate post-operative phase, but were nevertheless able to maintain their fluid and electrolyte balance by means of oral feeding. However, two dogs required 2 litres each of normal saline subcutaneously because of more severe vomiting. By the time the faecal collection was undertaken post-operatively the tendency to vomit had subsided and the diet was then taken normally.

Pyloroplasty was of the Heineke-Mikulicz type and was performed alone on seven dogs, the incision through the pylorus extending for $6 \mathrm{~cm}$. This was closed with a continuous $2 / 0$ chromic catgut suture.

Four dogs which had previously undergone anterior selective vagotomy later had pyloroplasty added; one of these died from peritonitis due to disruption of the pyloroplasty incision. Two further dogs, which had previously had pyloroplasty performed, later underwent anterior selective vagotomy. Thus there were available for study five dogs which had had anterior selective vagotomy together with pyloroplasty.

Control laparotomy on eight dogs was performed by a right subcostal incision, the wound being closed in the standard manner, no other procedure having been used.

- Lecturer in Surgery, Westminster Medical School, London.

\section{Results}

Total Vagotomy Alone.-There was some variability in the results, and the mean fat excretion rose from $0.31 \mathrm{~g} . / 24$ hours pre-operatively to $0.50 \mathrm{~g}$. after vagotomy (see Table).

Anterior Selective Vagotomy Alone.-As with total vagotomy, there was a slight rise in the mean fat excretion from a pre-operative value of $0.74 \mathrm{~g} . / 24$ hours to a post-operative level of $1.07 \mathrm{~g}$. (see Table).

Anterior Selective Vagotomy and Pyloroplasty.-There was a consistent and marked increase in fat excretion in each dog, the mean level rising from 0.93 to $3.82 \mathrm{~g} . / 24$ hours (see Table).

Pyloroplasty Alone.-With the exception of one animal, there was a marked increase in fat excretion, and the mean rose from $0.99 \mathrm{~g} . / 24$ hours before operation to $2.61 \mathrm{~g}$. after the pyloroplasty (see Table).

Faecal Fat Excretion Before and After Total Vagotomy, Anteriar Selective Vagotomy, Anterior Selective Vagotomy with Pyloroplasty, Pyloroplasty Alone, and Control Laparotomy

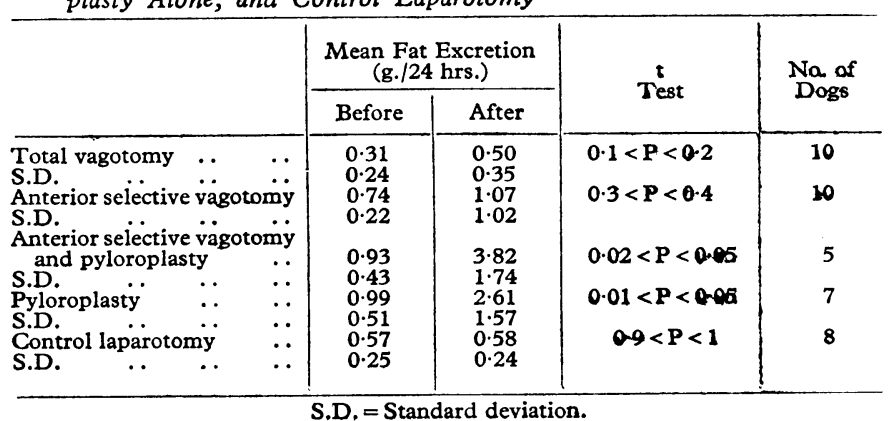

Control Laparotomy.-The excretion of fat remained constant before and after operation, the levels being 0.57 and 0.58 g. $/ 24$ hours respectively.

\section{Discussion}

The mechanism whereby the increase in fat excretion after vagotomy and pyloroplasty occurs had not hitherto been completely investigated. There are two possibilities: (1) defective digestion and (2) defective absorption.

In 10 dogs there was a slight mean increase in faecal fat excretion after total vagotomy compared with the pre-operative level ; this was not significant $(0.1<\mathrm{P}<0.2)$. It might be argued that after total vagotomy, in the dog as in man, the stomach is dilated and empties slowly. In spite of this, however, in the dogs investigated all food was eaten, and the weight of faeces passed per day after total vagotomy was not greatly below that before operation (23.42 and $19.16 \mathrm{~g} . / 24$ hours, respectively).

Information concerning the effect of vagotomy alone on faecal fat excretion in humans is conflicting. Some have found 
it to be increased (Fox and Grimson, 1950) and others unaltered (Butler and Eastham, 1965; Stammers and Williams, 1963). Because the excretion of fat was equally raised after vagotomy with pyloroplasty and vagotomy with gastro-jejunostomy, Logan (1964) inferred that the raised excretion of fat was due to the vagotomy.

In dogs, after total vagotomy alone, Golding, Mendoza, Aiello, Fierst, Solomon, and Enquist (1965) and Baldwin, Albo, Jaffe, and Silen (1965) showed that there was little effect on the absorption of ${ }^{131} \mathrm{I}$ triolein. Our results therefore agree both with these and with those of Stammers and Williams (1963) and of Butler and Eastham (1965) in humans.

The fact that total vagotomy by itself produces no alteration on fat excretion in dogs suggests that the vagal innervation to the gall-bladder and the biliary tree is not important in this respect. It is not surprising, therefore, to find that after anterior selective vagotomy the faecal fat excretion in 10 dogs was similar to that found after total vagotomy ; there was a slight rise in the mean fat excretion which was not significant $(0.3<$ $P<0.4$ ). This latter observation agrees with the results already noted in humans in that no difference was demonstrable between total and anterior selective vagotomy and pyloroplasty in terms of the excretion of fat (Wastell and Ellis, 1966).

When, in dogs, a pyloroplasty together with an anterior selective vagotomy is performed a significant $(0.02<\mathrm{P}<0.05)$ and consistent rise occurs in the excretion of fat. However, this result in the experimental dog is contrary to that found by Golding et al. (1965) using radioactive triolein ; they could not demonstrate significant depression of fat absorption after vagotomy alone or in combination with pyloroplasty. The difference may be explained by the different techniques used to estimate fat absorption. It was a striking fact that in our dogs after pyloroplasty, either with or without vagotomy, undigested pieces of liver would appear in the faeces, indicating that the ingested meal had not been reduced to a suitable form for digestion.

The first process in the digestion of fat is the reduction of ingested food to a more or less homogeneous chyme, the solid material having been broken down mechanically, and to some extent enzymatically, into smaller pieces. This process occurs in the muscular gastric antrum. Observing the isolated stomachs of rats, Armitage and Dean (1963) found the pressure developed in the antrum to be greater than that in the body of the stomach, and they noted that there was a functional sphincter separating the two. It may well be that the pylorus, after pyloroplasty, accepts much larger fragments of food-for example, the liver in our dogs-and conducts them into the duodenum before they have been adequately reduced in size. Thu's the food materials in these relatively large masses cannot be adequately digested, with a resultant decrease in absorption.

If this is the explanation of the increased excretion of fat after vagotomy and pyloroplasty the same should hold good for pyloroplasty alone. This was found to be the case. In seven dogs submitted to pyloroplasty alone there was a significant $(0.01<\mathrm{P}<0.05)$ increase in faecal fat after operation.
Once again pieces of undigested liver were noted in the faeces (the results in one animal ran counter to the rest in that, in spite of an adequate pvloroplasty, as judged by post-mortem examination, there was a small decrease in the post-operative faecal fat excretion). If radioactive-labelled triolein is used to assess fat absorption it is apparent that this is in a suitable physical form, that of an oil, for digestion and absorption to proceed. There is less need for it to be mechanically mixed in the antrum before it presents a suitably large surface area for the efficient action of lipase. This may be the explanation for the disparity between our results and those of other investigators. Although an elegant technique, radioactive labelling of an oil does not test the ability to absorb fat in a form constituting a normal diet.

Evidence of small-intestinal mucosal abnormality, suggesting a possible absorptive defect, has been described by Ballinger, Iida, Aponte, Wirts, and Goldstein (1964). However, in our dogs no histological abnormality of the small-bowel mucosa was noted, nor have either histological or histochemical changes in the intestinal mucosa of the vagotomized rat been found in our laboratory (Ellis and Pryse-Davies, unpublished observations).

\section{Summary}

Faecal fat excretion has been measured in dogs before and after total and anterior selective vagotomy alone and with pyloroplasty, pyloroplasty alone, and control laparotomy.

The results indicate that pyloroplasty is responsible for an increase in faecal fat excretion, whereas either total or anterior selective vagotomy alone is not.

I am grateful to Professor Harold Ellis for the suggestion on which this investigation is based, and for continued support and encouragement. I am also grateful to Professor E. C. Amoroso for facilities granted at the Royal Veterinary College, London; to Miss P. Torrens for helpful advice about the dietary régime; to Mrs. A. C. Kopec for statistical advice; and to Miss H. Scapetti for technical help. This work was partly supported by a grant from the Westminster Hospital Research Fund, and is part of the material submitted to the University of London for the degree of M.S.

\section{REPERENCES}

Armitage, A. K., and Dean, A. C. B. (1963). Gut, 4, 174.

Baldwin, J. N., Albo, R., Jaffe, B., and Silen, W. (1965). Surg. Gynec. Obstet., 120, 777 .

Ballinger, W. F., Iida, J., Aponte, G. E., Wirts, C. W., and Goldstein, F. (1964). Ibid., 118, 1305.

Butler, T. J., and Eastham, R. D. (1965). Gut, 6, 69.

Fox, H. J., and Grimson, K. S. (1950). F. Lab. clin. Med., 35, 362.

Golding, M. R., Mendoza, M., Aiello, R. G., Fierst, S. M., Solomon, N. A., and Enquist, I. F.' (1965). Amer. F. Surg., 109, 21.

Kamer, J. H. van de, Huinink, H. ten B., and Weyers, H. A. (1949). F. biol. Chem., 177, 347.

Logan, H. (1964). Gut, 5, 188.

Stammers, F. A. R., and Williams, J. A. (1963). Partial Gastrectomy : Complications and Metabolic Consequences. Butterworths, London. Wastell, C., and Ellis, H. (1966). Brit. med. F., 1, 1194. 